\title{
Variabilidade genética de Xanthomonas Axonopodis Pv. Passiflorae
}

\author{
Andreia K. Nakatani ${ }^{1}$, Ricardo Lopes ${ }^{2}$, Luis E.A. Camargo ${ }^{3}$
}

${ }^{1}$ Centro Avançado de Pesquisa Tecnológica do Agronegócio de Citros Sylvio Moreira, CAPTACSM, Rodovia Anhangüera Km 158, Cx Postal 04, 13490-970,Cordeirópolis, SP. aknakata@hotmail.com. ${ }^{2}$ Embrapa Amazônia Ocidental, Rod. AM 010, Km 29, Caixa Postal 319, CEP 69011970, Manaus, AM. Ricardo.lopes@cpaa.embrapa.br. ${ }^{3}$ Departamento de Entomologia, Fitopatologia e Zoologia Agrícola, Escola Superior de Agricultura "Luiz de Queiroz" - Universidade de São Paulo, Caixa Postal 09, CEP 13418-900, Piracicaba, SP. leacamar@carpa.ciagri.usp.br. *Parte da dissertação de mestrado da primeira autora apresentada à Escola Superior de Agricultura "Luiz de Queiroz".

Autor para correspondência: Andreia Kazumi Nakatani

Data de chegada: 07/12/2006. Aceito para publicação em: 23/09/2008

\section{RESUMO}

Nakatani, A.K., Lopes, R. \& Camargo, L.E.A. Variabilidade genética de Xanthomonas axonopodis pv. passiflorae. Summa Phytopathologica, v.35, n.2, p.116-120, 2009

A mancha bacteriana, causada por Xanthomonas axonopodis pv. passiflorae, é uma das mais importantes doenças do maracujazeiro, podendo limitar a produção dessa frutífera em algumas regiões do País. O uso de resistência genética e controle químico, juntamente com o emprego de medidas de exclusão, são as práticas de controle da doença mais recomendadas. Para o desenvolvimento de variedades resistentes é necessário conhecer tanto a variabilidade genética do hospedeiro quanto do patógeno. Nesse trabalho foi estudada a variabilidade de cinqüenta isolados patogênicos de Xanthomonas axonopodis pv. passiflorae, coletados em quatro diferentes locais no estado de São Paulo. No estudo da variabilidade genética foram usados dados de marcadores moleculares RAPD (Random Amplified Polymorphic DNA), os quais foram usados para o cálculo do coeficiente de similaridade de Dice entre os isolados, análise de variância molecular (AMOVA) entre e dentro das populações e agrupamento dos isolados pelo método UPGMA. Para análise da agressividade foram usados cinco isolados, mais divergentes, baseado no dendrograma. O coeficiente de similaridade variou entre 0,6887 e 0,9688 . Na análise de agrupamento, os isolados foram separados em sete grupos e não houve relação evidente entre local de coleta com a composição dos grupos. Na análise da variância molecular (AMOVA) verificou-se que a maior parte da variabilidade genética está dentro das populações $(89,4 \%)$ e apenas $10,6 \%$, entre populações. Os resultados da análise de agrupamento e da AMOVA indicam que existe grande fluxo gênico entre isolados bacterianos nas regiões analisadas. No teste de patogenicidade verificou-se diferença significativa de agressividade entre os isolados. Os resultados demonstram a importância do conhecimento da variabilidade genética e da agressividade na seleção dos isolados para serem utilizados em testes de resistência genética no desenvolvimento de variedades resistentes.

Palavras-chave adicionais: Diversidade, Bacteria, Agressividade.

\section{ABSTRACT}

Nakatani, A.K., Lopes, R. \& Camargo, L.E.A. Genetic variability of Xanthomonas axonopodis pv. passiflorae. Summa Phytopathologica, v.35, n.2, p.116-120, 2009

The bacterial spot, caused by Xanthomonas axonopodis pv. passiflorae, is one of the most important diseases of passion fruit, which can drastically limit the production in some regions of Brazil. The use of genetic resistance, chemical control and the adoption of exclusion measures are the more recommended practices for the control of this disease. To produce the resistant varieties knowledge about the variability of both host and pathogen is needed. In this study, we investigated the variability of 50 pathogenic isolates of $X$. axonopodis pv. passiflorae, collected from four production areas in São Paulo State. We used RAPD markers (Random Amplified Polymorphic DNA) for identification of the degree of genetic similarities through dice coefficient, analysis of molecular variance
(AMOVA), among as well as within populations and clustering by the UPGMA method. Based on the clustering, the five more divergent isolates were selected for agressiveness trials. The similarity coefficient ranged from 0.6887 to 0.9688 . Clustering analysis grouped the isolates in seven categories and neither apparent correlation was identified among their geographical origin no clustering pattern. The AMOVA data showed that the variability within and among populations were $89.4 \%$ and $10.6 \%$ respectively. The clustering analysis indicated genic flow among the different production areas. The results highlights the importance of taking into consideration the bacterial genetic variability of this bacterium as well as its agressiveness during the selection of resistant varieties.

Keywords: Diversity, Bacterium, Agressiveness.

O maracujazeiro é uma planta tropical de sabor exótico e rico em suas propriedades alimentícias, ornamentais e medicinais. A expansão da cultura no Brasil, embora em ritmo crescente, encontra limitações, principalmente associadas a fatores fitossanitários. Entre esses destaca- se a bacteriose do maracujazeiro, doença causada por Xanthomonas axonopodis pv. passiflorae, a qualé de difícil controle e de ocorrência generalizada no Brasil (22). A doença foi constatada pela primeira vez no Brasil, em 1968, na região de Araraquara, Estado de São Paulo (24) 
e já foi relatada em todas as regiões produtoras do país (30). Em 2000, a denominação da bactéria foi alterada de Xanthomonas campestris pv. passiflorae (Pereira) Dye para Xanthomonas axonopodis pv. passiflorae (8).

A doença manifesta-se principalmente nas partes tenras ou suculentas dos tecidos, estendendo-se aos elementos vasculares adjacentes podendo, além de inutilizar os frutos para o consumo, acarretar a destruição total da planta afetada $(15,29,30)$.

A medida de controle da doença de maior importância atualmente é a utilização de mudas e sementes sadias. No entanto, no Estado de São Paulo, a bacteria está disseminada em praticamente todas as regiões onde se cultiva comercialmente o maracujazeiro, o que constitui um entrave para obtenção de material de propagação sadio (18) e o controle químico não tem se mostrado eficiente (31). O desenvolvimento de variedades resistentes é apontado como a medida mais efetiva no controle da doença por não causar impactos ambientais e ser de reduzido custo para o produtor (29).

Embora o conhecimento da resistência genética de Passiflora à bacteriose do maracujazeiro ainda seja incipiente, resultados obtidos têm indicado variabilidade do caráter dentro da espécie e herança quantitativa $(13,17,19)$. Para que a resistência genética seja utilizada de maneira eficiente no desenvolvimento de variedades que apresentem resistência duradoura e de amplo espectro é necessário tanto o conhecimento das fontes de resistência na espécie hospedeira como da variabilidade da agressividade na população do patógeno. Os isolados bacterianos a serem utilizados nos testes de agressividade deve ser selecionados a partir do estudo da variabilidade genética do patógeno, procurando, dessa maneira, representar a variabilidade existente nos ambientes de cultivo $(3,11,20,25)$.

Os marcadores moleculares têm sido eficientes na análise da variabilidade genética de patógenos, incluindo estudos da variabilidade genética de diferentes espécies de Xanthomonas. Verdier et al. (32), utilizando a técnica de RFLP, de sondas de $16 \mathrm{~S}$ e $23 \mathrm{~S}$ RNAm encontraram alta variabilidade genética em isolados de Xanthomonas axonopodis pv. Manihotis provenientes da América do sul, região de origem da mandioca. Para essa mesma bactéria, Restrepo et al. (27), utilizando marcadores RFLP, rep-PCR e AFLP, encontraram resultados semelhantes. Raymundo et al. (26), estudando diversidade genética em populações de Xanthomonas oryzae pv. oryzicola isoladas de arroz, encontraram alta variabilidade entre e dentro das populações da bactéria. Gonçalves \& Rosato (8), utilizando a técnica RAPD (random amplified polymorphic DNA), estudaram a diversidade genética de Xanthomonas axonopodis pv. passiflorae entre isolados de diferentes Estados brasileiros.

O objetivo do presente trabalho foi avaliar a variabilidade genética e patogênica de isolados de Xanthomonas axonopodis pv. passiflorae obtidos a partir de plantas de maracujá em plantios de quatro diferentes municípios do Estado de São Paulo.

\section{MATERIAL E MÉTODOS}

\section{Obtenção e caracterização de isolados de Xanthomonas axonopodis pv.passiflorae}

Amostras de folhas sintomáticas de maracujazeiro foram coletadas em três propriedades comerciais e em uma não produtora comercial de maracujá, localizados nos municípios de Vera Cruz (VCR), Holambra (HOL), São Miguel Arcanjo (SMA e SMD) e São Pedro (SPD), Estado de São Paulo, neste último em propriedade não produtora. De cada propriedade foram obtidos 10 isolados de diferentes plantas de maracujá azedo. Na propriedade situada em São Miguel Arcanjo foram também feitas coletas em maracujá doce e, para verificar a ocorrência de infecção por mais de um haplótipo na mesma planta, foram coletadas três folhas sintomáticas em uma mesma planta de maracujá azedo.

Os isolamentos bacterianos foram realizados no Laboratório de Genética Molecular do Departamento de Entomologia, Fitopatologia e Zoologia Agrícola da ESALQ-USP.

Os isolados obtidos foram inoculados artificialmente em plantas de maracujá. A patogenicidade dos isolados foi testada por meio de inoculações artificiais com suspensões bacterianas obtidas a partir de colônias puras cultivadas em meio nutriente agar (NA) (3 g extrato de carne, $8 \mathrm{~g}$ de peptona, $15 \mathrm{~g}$ de ágar e $1000 \mathrm{ml}$ de água destilada, $\mathrm{pH} 7,0$ ) durante 48 horas. As colônias foram lavadas com água esterilizada e a suspensão bacteriana padronizada em espectrofotômetro (Hitachi U2000) a $\mathrm{OD}_{600}=0,3$, o que representa uma concentração aproximada de $10^{8}$ unidades formadoras de colônias $/ \mathrm{ml}$ (u.f.c $/ \mathrm{ml}$ ). Foram utilizadas plantas de maracujá azedo com 90 dias de idade, cultivadas em vasos e mantidas em casa de vegetação. $O$ método utilizado foi o do corte com tesoura previamente imersa em suspensão bacteriana (12). Para cada isolado, foram inoculadas duas plantas e, no caso da testemunha, o inóculo foi substituído por água. Após a inoculação, as plantas foram submetidas à câmara úmida por 48 horas. Os sintomas foram avaliados 10 dias após a inoculação com base na presença ou ausência de lesões típicas. Após o reisolamento e teste de patogenicidade, foi feita a extração do pigmento xanthomonadina, o qual é produzido por todos os membros do gênero Xanthomonas (10), A xanthomonadina é identificada por seu espectro de absorção apresentando um pico máximo de absorbância entre 442 e 446 nm- dois “ombros" a 467 e 420 $\mathrm{nm}$, sendo por isso utilizado para confirmação do gênero dos isolados.

Análise de marcadores moleculares RAPD

A extração do DNA bacteriano foi feita segundo protocolo de Ausubel (2). Após a extração, o DNA de cada um dos 50 isolados bacterianos foi submetido a amplificações por PCR com os oligonucleotídeos OPAA 1, OPAA 4, OPAA 6, OPAA 9, OPAA 17, OPAA 16 , OPAA 7, OPAA 12, OPAA 2, OPAA 3, OPAA 15 e o OPAB 1, OPAB 14, OPAB 17, OPAB 05) produzidos pela Operon Technologies Inc. (Alameda, CA, EUA) em termociclador PTC-100 (MJ. Research, Alameda, CA, EUA), com adaptações às condições descritas por Gomes (7). As reações foram realizadas em volume final de $20 \mu 1$, contendo 30ng de DNA de cada amostra, 30 ng do iniciador, $1 \mathrm{U}$ de Taq DNA polimerase (Gibco BRL, Grand Island, NY, EUA), $2,5 \mu 1$ de 10x de tampão e $0,2 \mathrm{mM}$ de mistura de dNTP e 3,0 mM de $\mathrm{MgCl}_{2}$. As amostras foram submetidas à desnaturação inicial a $92^{\circ} \mathrm{C}$ por 2 minutos, seguida de 40 ciclos a $92^{\circ} \mathrm{C}$ por 1 minuto, $37^{\circ} \mathrm{C}$ por 2 minutos e $72{ }^{\circ} \mathrm{C}$ por 2 minutos e ao final, uma extensão de $72^{\circ} \mathrm{C}$ por 3 minutos. Os produtos da amplificação foram submetidos à eletroforese em tampão TBE $1 \mathrm{X}$ a $5 \mathrm{v} / \mathrm{cm}$, em gel de agarose $1,5 \%$ contendo brometo de etídeo na concentração de $5 \mu \mathrm{g} / \mathrm{ml}$. Os géis foram visualizados sob luz ultravioleta e fotografados em sistema digital com aparelho fotodocumentador Pharmacia Biotech Image Master VDS (Pharmacia Biotech, San Francisco, CA, EUA).

Análise da variabilidade genética dos isolados bacterianos

Os géis de RAPD foram analisados para presença ou ausência de bandas no gel, usando o código 1 para representar a amplificação do fragmento (presença da banda no gel) e 0 , para ausência de amplificação (ausência da banda no gel), construiu-se uma matriz binária e calculouse a similaridade genética entre os isolados utilizando o coeficiente de 
Dice, o qual é obtido pela expressão $D=2 a / 2 a+b+c$, sendo $a$ coincidência do tipo 1-1, $b$ discordância 1-0 e $c$ discordância 0-1. Utilizando os coeficientes de similaridade genética, os isolados foram agrupados pelo método UPGMA (Unweighted Pair-Group Method with Arithmetical Average).

Para análise da variabilidade genética dos isolados entre e dentro dos diferentes locais de coleta foi realizada a Análise de Variância Molecular (6). A partir das freqüências dos fragmentos amplificados nas populações foi calculada a distância entre as mesmas. As análises de foram realizadas no Programa Genes - Aplicativo Computacional em Genética e Estatística (4).

\section{Avaliação da agressividade dos isolados bacterianos}

A partir dos coeficientes de similaridade genética e da análise de agrupamento, foram selecionados, com base na divergência genética, geneticamente diferentes, cinco isolados para avaliação da agressividade com inoculações artificiais. As inoculações foram realizadas em Novembro de 1999 e Maio de 2000 em folhas de plantas de maracujá azedo (Passiflora edulis f. flavicarpa Deg.) cultivar Sul Brasil com 90 dias de idade, cultivadas em vasos e mantidas em casa de vegetação.

Os isolados bacterianos foram multiplicados em meio NA a $28^{\circ} \mathrm{C}$ por 72 horas e as suspensões aquosas usadas para as inoculações foram padronizadas em espectrofotômetro (Hitachi U- 2000) a $\mathrm{OD}_{600}=0.3$ (aproximadamente $10^{8} \mathrm{UFC} / \mathrm{mL}$ ). Para a inoculação empregou-se o método do corte das folhas a $5 \mathrm{~cm}$ da extremidade com tesoura previamente imersa em suspensão bacteriana (12). Na testemunha, o inóculo foi substituído por água. Após a inoculação, as plantas permaneceram em câmara úmida $\left(22^{\circ} \mathrm{C} \pm 2\right)$ por 48 horas. Foram realizados dois experimentos, conduzidos no delineamento estatístico em blocos ao acaso, com 5 repetições, sendo cada parcela constituída por um vaso contendo duas plantas.

Vinte dias após as inoculações, as folhas inoculadas foram removidas e quantificada a área foliar lesionada (AFL) $\mathrm{em}^{2}$ e para tanto, a área da lesão foi desenhada em folha plástica transparente e avaliada usando-se um medidor de área foliar (Li-Cor, Li-3100, Nebraska, EUA). Os dados foram submetidos à análise de variância e testes de médias (Tukey, $\mathrm{P}<5 \%$ ), probalidade menor que $5 \%$.

\section{RESULTADOS E DISCUSSÃO}

\section{Caracterização e patogenicidade dos isolados bacterianos}

Todos os isolados bacterianos apresentaram o pigmento amarelado denominado de xanthomonadina, cujo espectro de absorção desse pigmento apresenta um pico máximo de absorbância entre 442 e 446 $\mathrm{nm}$, além de dois "ombros" a 467 e $420 \mathrm{~nm}$, tendo sido classificados como pertencente ao gênero Xanthomonas (10).

As plantas de maracujá (Passiflorae edulis f. flavicarpa) inoculadas artificialmente desenvolveram sintomas da doença. A partir do reisolamentos foram produzidas colônias bacterianas semelhantes as usadas para inoculação, fechando os postulados de Koch.

\section{Variabilidade genética dos isolados bacterianos}

A amplificação do DNA genômico dos 50 isolados de Xanthomonas axonopodis pv. passiflorae com quinze oligonucleotídeos gerou 113 fragmentos, dos quais $71(62,8 \%)$ foram polimórficos. Os perfis de DNA obtidos com a utilização do oligonucleotídeo OPAA12 encontram-se na Figura 1.

O menor valor de similaridade genética, $\mathrm{D}=0,6887$, foi observado entre os isolados VCR06 e SMD05, coletados nos municípios de Vera Cruz, em maracujá azedo, e em São Miguel Arcanjo, em maracujá

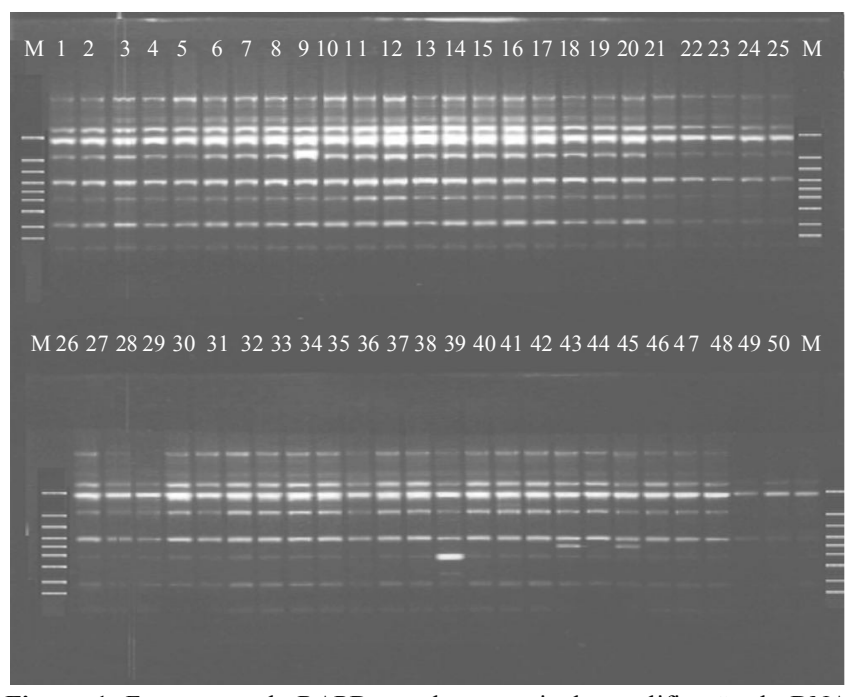

Figura 1. Fragmentos de RAPD gerados a partir da amplificação do DNA genômico de 50 isolados de Xanthomonas axonopodis pv. passiflorae com o oligonucleotídeo OPAA12.

doce. Os maiores valores de similaridade, $\mathrm{D}=0,9688$, foram observados para os isolados SMA05 e SPD06, provenientes de maracujá azedo e de maracujá doce coletados nos municípios de São Miguel Arcanjo e São Pedro, respectivamente. Gonçalves \& Rosato (8), utilizando marcadores moleculares, verificaram a existência de elevado grau de polimorfismo entre isolados de Xanthomonas axonopodis pv. passiflorae coletados em sete Estados brasileiros, com níveis de similaridade variando de 0,35 a 0,85 , inferiores aos observados no presente trabalho, de 0,6887 a 0,9688 .

O agrupamento dos isolados pelo método UPGMA é apresentado na Figura 2. A análise de agrupamento tem-se por finalidade dividir os isolados em grupos com maior similaridade. Utilizando como ponto de corte para divisão dos grupos $90 \%$ do valor obtido na formação do grupo final, são separados sete grupos. O agrupamento observado demonstrou que o local de coleta não é fator preponderantemente na determinação da similaridade genética dos isolados, pois verifica-se que não houve relação evidente entre local de coleta e composição de grupos. Os isolados de Holambra (HOL) e de São Pedro (SPD) distribuiram-se por cinco grupos; os de Vera Cruz (VCR) e de São Miguel Arcanjo coletados em maracujá doce (SMD), por seis grupos e os de São Miguel Arcanjo coletados em maracujá azedo (SMA) por todos os sete grupos.

Gonçalves \& Rosato (8) encontraram relação entre região de coleta e similaridade genética de isolados de $X$. axonopodis pv passiflorae, sendo os grupos formados em função da região de coleta. Contudo, os autores, realizaram as amostragens em regiões mais dispersas geograficamente, localizados em sete estados brasileiros, no presente trabalho, entretanto, a coleta das amostras foi limitada ao estado de São Paulo, oque poderia explicar os valores de similaridade genética encontrados.

A variabilidade observada nas populações de $X$. $a$. pv. passiflorae é explicada pelo fato de ser o Brasil um importante centro de diversidade do gênero Passiflora (5), e geralmente os centros de diversidade dos hospedeiros também são centros de diversidade dos patógenos (16).

A análise de variância molecular (Quadro 1) demonstrou que a maior parte da variabilidade genética dos isolados está dentro das populações, $89,4 \%$, embora exista diferenças significativas entre as populações, $10,6 \%$. Abaixa proporção da variabilidade entre em relação 


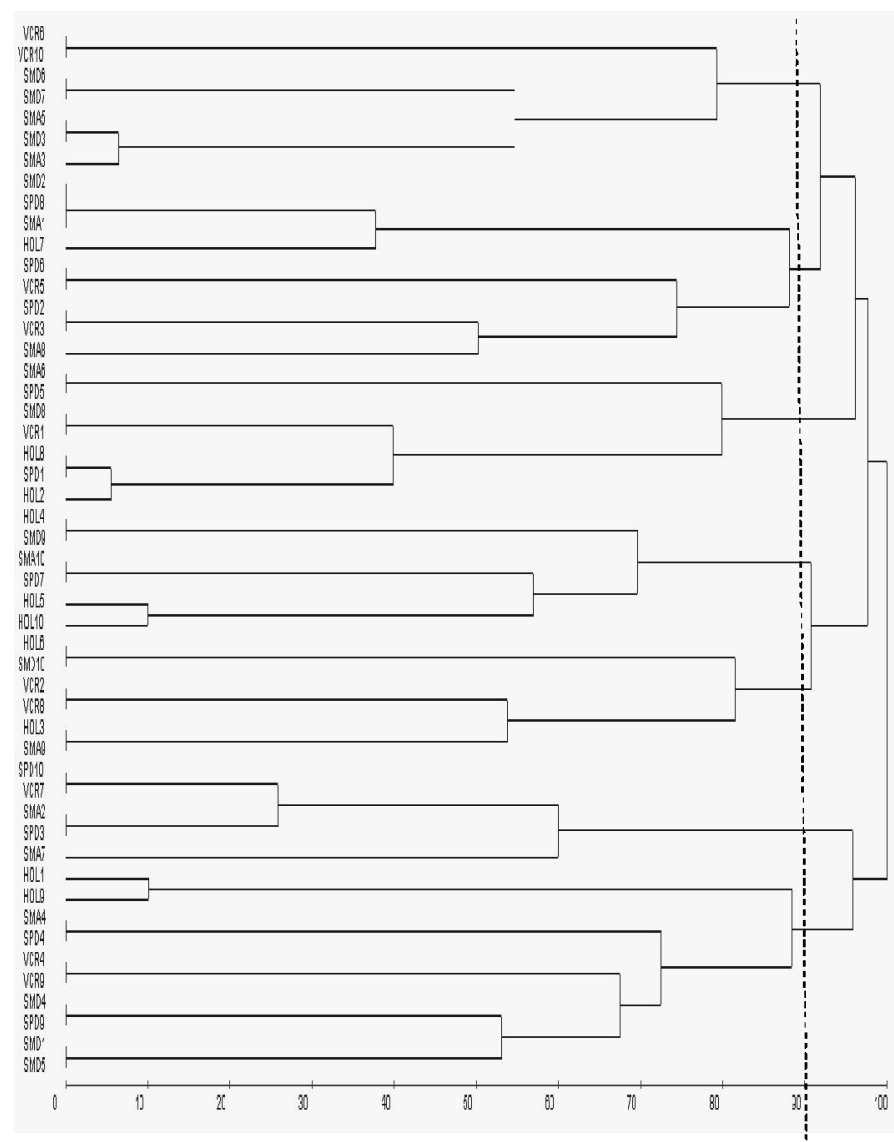

Figura 2. Agrupamento hierárquico dos 50 isolados de Xanthomonas axonopodis pv. passiflorae pelo método UPGMA usando o coeficiente de similaridade de Dice calculado a partir de 73 locos RAPD. Os valores numéricos abaixo do dendograma representam as distâncias convertidas em percentagens, tomando como base o valor da distância do último isolado com o grupo igual a $100 \%$. Os símbolos a esquerda representam os isolados analisados, sendo as letras usadas para identificar o local de coleta: Hol - Holambra, VCR - Vera Cruz, SMA - São Miguel Arcanjo (maracujá azedo), SMD - São Miguel Arcanjo (maracujá doce) e SPD - São Pedro e os números os isolados.

a dentro de populações corrobora com o agrupamento obtido que não evidenciou diferenciação genética entre populações indicando que existe grande fluxo gênico entre as regiões analisadas. $\mathrm{O}$ fluxo gênico, no caso de plantios do Estado de São Paulo, é facilitado pela troca de materiais vegetais (mudas e sementes) entre as regiões produtoras. No início dos plantios de maracujá na região de São Miguel Arcanjo, por exemplo, os produtores buscavam sementes de áreas produtoras em Vera Cruz ou, ainda, obtinham sementes a partir de frutos comercializados no mercado. Intensificação de fluxo gênico por meio de trânsito de sementes contaminadas é possível no caso de $X$. a. passiflorae, a exemplo de outras espécies do gênero que sabidamente são disseminadas por esta via, tal como Xanthomonas axonopodis pv. vesicatoria (14) e Xanthomonas campestris pv. cerealis. Segundo Dias (5), a incidência de $X$. a. pv. passiflorae em sementes pode chegar a $1,8 \%$.

A similaridade entre as populações (locais de coleta), calculada a partir das freqüências dos fragmentos amplificados (bandas), variou de 0,8255 , entre as populações HOL e SPD, as mais similares, a 0,8735, entre SMA e SPD, as mais divergentes.

Os isolados SMA07, SMA08 e SMA09, coletados na mesma
Quadro 1. Análise da variância molecular (AMOVA) aplicada a 71 locos RAPD analisados em Xanthomonas axonopodis pv. passiflorae isolada em quatro áreas de maracujá-amarelo e uma de maracujá-doce.

\begin{tabular}{lccccc}
\hline $\begin{array}{c}\text { Fontes de } \\
\text { Variação }\end{array}$ & $\begin{array}{c}\text { Graus de } \\
\text { liberdade }\end{array}$ & $\begin{array}{c}\text { Quadrados } \\
\text { Médios }\end{array}$ & $\begin{array}{c}\text { Estimativa dos } \\
\text { componentes de variância }\end{array}$ & $\begin{array}{c}\text { Porcentagem } \\
\text { da variância }\end{array}$ & $\mathrm{P}^{1}$ \\
\hline Entre & 4 & 20,44 & 1,11 & 10,6 & $<0,01$ \\
Dentro & 45 & 9,36 & 9,36 & 89,4 & $<0,01$ \\
Total & 49 & 10,22 & 10,47 & 100,0 & \\
\hline
\end{tabular}

${ }^{1}$ Probabilidade de que o valor estimado do componente de variação seja ao acaso. Teste realizado com 1.000 permutações.

planta de maracujá azedo no município de São Miguel Arcanjo, foram atribuídos a grupos diferentes demonstrando infecção de diferentes haplótipos na mesma planta.

\section{Agressividade dos isolados bacterianos}

A análise da patogenicidade foi realizada utilizando-se cinco isolados; VCR1, SMA6, SMD1, HOL8 e SPD10. As médias da variável AFL dos cinco isolados avaliados foram comparadas pelo teste Tukey $(\mathrm{P}<0,05)$ (Figura 3).

O isolado SMA6 produziu maior AFL; contudo, o valor observado não diferiu estatisticamente dos valores da AFL obtidos para os isolados SPD10 e HOL8, mas foi estatisticamente superior aos dos isolados VCR1 e SMD1. O isolado SMD1 apresentou o menor valor de AFL, mas não diferiu estatísticamente da AFL do isolado VCR1. Os valores de AFL observados para todos os isolados diferiram estatisticamente da testemunha. O resultado indica a existência de variabilidade na agressividade dos isolados quando inoculados em maracujá azedo, diferente do que foi verificado por Gonçalves \& Rosato (8), que não encontraram variação da severidade em testes de patogenicidade de $X$. axonopodis pv. passiflorae em $P$. alata. Do ponto de vista prático, os resultados obtidos indicam a necessidade de considerar a variabilidade do patógeno na avaliação de genótipos de maracujá em programas de seleção de cultivares resistentes. O uso de isolados mais agressivos é desejável, pois proporciona mais rigor na seleção e melhor discernimento entre genótipos resistentes e

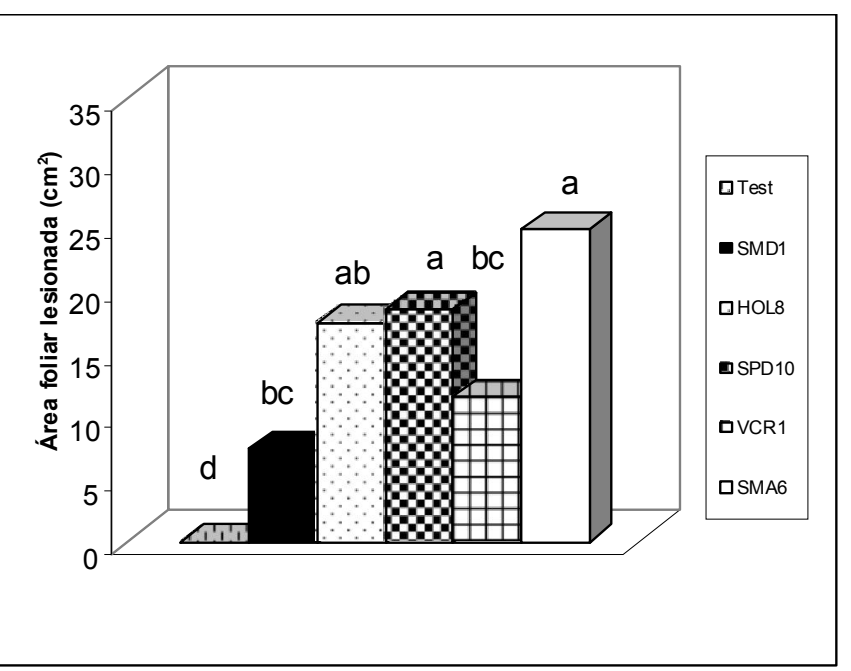

Figura 3. Agressividade de cinco isolados de Xanthomonas axonopodis pv. passiflorae em plantas de maracujá azedo avaliada no experimento dois, a partir da área foliar média lesionada (AFL), 20 dias após a inoculação. Barras com a mesma letra indicam que os valores da AFL não diferem estatisticamente entre si, pelo teste de Tukey, ao nível de 5\% de probabilidade. 
suscetíveis.

Variações em agressividade ocorrem aparentemente em diferentes isolados de praticamente todas as bactérias fitopatogênicas como Xanthomonas axonopodis pv. manihotis (1), Xanthomonas campestris pv. campestris (9) e Ralstonia solanacearum (21). No caso do maracujá, a variabilidade em agressividade aqui relatada pode explicar informações contraditórias encontradas na literatura sobre a resistência de espécies de Passiflora a $X$. axonopodis pv. passiflorae. Rodrigues Neto et al., (28) relataram uma maior suscetibilidade de $P$. alata em relação a Passiflorae edulis f. flavicarpa, ao passo que segundo Oliveira et al (23) P. alata é aparentemente mais tolerante à bacteriose. Considerando que existem mais de três centenas de espécies de passiflorae, é possível que exista variabilidade na agressividade de Xanthomonas axonopodis pv. passiflorae. Por outro lado, sendo a América do Sul centro de diversidade do maracujá, é razoável supor que exista grande variabilidade para resistência a $X$. a. passiflorae em Passiflorae edulis f. flavicarpa com potencial para uso no desenvolvimento de variedades resistêntes.

\section{REFERÊNCIAS BIBLIOGRÁFICAS}

1. Alves, M.L.B.; Takatsu, A. Variabilidade em Xanthomonas campestris pv. manihotis. Fitopatologia Brasileira, Brasília, v.9, n. 3, p.485-494, 1984.

2. Ausubel, F.M.; Brent, R.; Kingston, R.E.; Moore, D.D.; Seidman, J.G.; Smith, J.A; Struhl, K. Current Protocols in Molecular Biology. New York: Greene, 900p. 1992.

3. Blodgett, J.T.; Stanosz, G.R. Differences in aggressiveness of Sphaeropsis sapinea RAPD marker group isolates on several conifers. Plant Disease, St Paul, v.83, n. 9, p.853-856, 1999.

4. Cruz, C.D. Programa genes: aplicativo computacional em genética e estatística (versão Windows). Viçosa, MG: 2001. 648p.

5. Dias, S.C. Morte prematura do maracujazeiro amarelo (Passiflora edulis f. flavicarpa) causada por patógenos que afetam a parte área da planta. 1990. 137f. Dissertação (Mestrado em Fitopatologia)- Universidade de Brasília, Brasília.

6. Excoffier, L.; Smouse, P.E.; Quattro, J.M. Analisys of molecular variance inferred from metric distances among DNA haplotypes: application to human mitochondrial DNA restriction data. Genetics, Austin, v.131, n. 2, p.479-491, 1992.

7. Gomes, L.H.; Duarte, K.M.R.; Argueso, J.L.; Echeverrigaray, S.; Tavares, F.C.A. Methods for yeast characterization from industrial products. Food Microbiology, Amsterdam, v.17, n.2, p.217-223, 2000.

8. Gonçalves, E.R.; Rosato, Y.B. Genotypic characterization of xanthomonad strains isolated from passion fruit plants (Passiflora spp.) and their relatedness to different Xanthomonas species. International Journal of Systematic and Evolutionary Microbiology, Reading, v.50, p.811-821, 2000

9. Henz, G.P.; Takatsu, A.; Reifschneider, F.J.B. Avaliação de métodos de inoculação de Xanthomonas campestris patovar campestris para detecção de fontes de resistência em brássicas. Fitopatologia Brasileira, Brasília, v.13, n.3, p.207-210, 1988.

10. Irey, M.S.; Stall, R.E. Value of xanthomonadins for identification of pigmented Xanthomonas campestris pathovars. In: Proc. Fifth Int. Conf. Plant Path. Bactéria. Cali, Colômbia, 1982, p. 85-95

11. Jaunet, T.J.; Wang, J.F. Variation in genotype and aggressiveness of Ralstonia solanacearum race 1 isolated from tomato in Taiwan. Phytopathology. St Paul, v.89, n. 4, p.320-327, 1999.

12. Kauffman, H.E.; Reddy, A.P.K.; Hsieh, S.P.Y.; Merca, S.D. An improved technique for evaluating resistance of rice varieties to Xanthomonas oryzae. Plant Disease Reporter, St Paul, v.57, n.6, p.537-541, 1973.

13. Kuroda, N.H. Avaliação do comportamento quanto à resistência de espécies e progênies de maracujazeiro a Xanthomonas passiflorae. 1981. 45f (Trabalho de conclusão de Curso)-Faculdade de Ciências Agrárias e Veterinária, Jaboticabal.

14. Leite Junior, R.P.; Jones, J.B.; Somodi, G.C.; Minsavage, G.V.; Stall, R.E. Detection of Xanthomonas campestris pv. vesicatoria associated with pepper and tomato seed by DNA amplification. Plant Disease, St Paul, v.79, n.9, p.917-922, 1995.

15. Leite Jr., R.P. Bacteriose do maracujazeiro e estratégias para seu controle. In: Reunião técnica de pesquisa em maracujazeiro, 3., 2002, Viçosa. Anais, Viçosa: UFV, 2002. p.97-98.

16. Leppik, E.E. Gene centers of plants as sources of disease resistance. Annual Review of Phytopathology, Palo Alto, v.8, p.323-344, 1970

17. Lopes, R.; Lopes, M.T.G.; Carneiro, M.S.; Matta, F.P.; Camargo, L.E.A.; Vieira, M.L.C. Linkage and mapping of resistance genes to Xanthomonas axonopodis pv. passiflorae in yellow passion fruit. Genome, Ottawa, v.49, n.1, p.17-29, 2006.

18. Malavolta Jr., V.A. Bacterioses do maracujazeiro. In: Simpósio Brasileiro sobre a Cultura do Maracujá, 5., 1998, Jaboticabal. Anais. Jaboticabal: Funep, 1998. p.217-229.

19. Matta. F.P. Mapeamento de QRL para Xanthomonas axonopodis pv. passiflorae em maracujá-amarelo (Passiflora edulis Sims f. flavicarpa Deg. ). 2005. 230f. Tese (Doutorado em Genética e Melhoramento de Plantas) Escola Superior de Agricultura "Luis de Queiroz"Universidade de São Paulo, Piracicaba.

20. Miedaner, T.; Schilling, A.G.; Geiger, H.H. Molecular genetic diversity and variation for aggressiveness in populations of Fusarium graminearum and Fusarium culmorum sampled from wheat fields in different countries. Journal Phytopathology, Berlin, v.149, n.11 p.641-648, 2001.

21. Morgado, H.S.; Lopes, C.A.; Takatsu, A. Virulência de isolados de Pseudomonas solanacearum à berinjela. Fitopatologia Brasileira, Brasília, v. 17, n.4, p.430-434, 1992

22. Oliveira, J.C.; Ruggiero, C. Aspectos sobre o melhoramento do maracujazeiro amarelo. In: Simpósio Brasileiro sobre a Cultura do Maracujá, 5., 1998, Jaboticabal. Anais. Jaboticabal: Funep, 1998. p.291310 .

23. Oliveira, J.C.; Salomão, T.A.; Ruggiero, C.; Rossini, A. Observações sobre o cultivo de Passiflora alata Ait. (maracujá-guaçu). Revista Brasileira de Fruticultura, Jaboticabal, v.2, n.1, p.59-63, 1980.

24. Pereira, A. L. G. Uma nova doença bacteriana do maracujá (Passiflora edulis Sims) causada por Xanthomonas passiflorae n. sp. Arquivos Instituto Biológico, São Paulo, v.36, p.163-174, 1969.

25. Pêros, J.P.; Berger, G. Genetic structure and variation in aggressiveness in European and Australian populations of the grapevine dieback fungus, Eutypa lata. European Journal of Plant Pathology, The Netherlands, v.109, n.9 p.909-919, 2003

26. Raymundo, A.K.; Briones Jr., A.M.; Ardales, E.Y.; Perez, M.T.; Fernandez, L.C.; Leach, J.E.; Mew, T.W.; Ynalvez, M.A.; McLaren, C.G.; Nelson, R.J. Analysis of DNA polymorphism and virulence in Philippine strains of Xanthomonas oryzae pv. oryzicola. Plant Disease, St Paul, v.83, n.5, p.434-440, 1999.

27. Restrepo, S.; Vélez, C.M.; Verdier, V. Measuring the genetic diversity of Xanthomonas axonopodis pv. manihotis within different fields in Colombia. Phytopathology, St Paul , v.90, n.7, p.683-690, 2000.

28. Rodrigues Neto, J.; Sugimori, M.H.; Malavolta Jr., V.A. Infecção natural em Passiflora alata Ait. por Xanthomonas campestris pv. passiflorae. Summa Phytopathologica, Jaguariúna, v.10, n.1, p.50, 1984.

29. Santos, C.C.F.; Santos Filho, H.P. Doenças causadas por bactérias In: Santos Filho, H.P.; Junqueira, N.T.V. (Ed.). Maracujá: fitossanidade. Brasília: Embrapa informação Tecnológica, 2003. n.32, p.2224.

30 Teixeira., C. G. Cultura. In: Teixeira, C.G.; Castro, J.V.; Tocchini, R.P.; Nisida, A.A.L.C.; Hashizume, T.; Medina, J.C.; Turatti, J.M.; Leite. S.S.F.; Bliska, M.M.; Garcia, A.E.B. Maracujá: cultura, matéria prima, processamento e aspectos econômicos. Série Frutas Tropicais, 9, 2.ed. 1994. p.3-142.

31. Torres Filho. J.; Ponte, J.J. Estudo sobre o controle da bacteriose ou "morte precoce" (Xanthomonas campestris pv. passiflorae) do maracujá amarelo (Passiflora edulis f. flavicarpa). Fitopatologia Brasileira, Brasília, v.19, n.1, p.34-38, 1994.

32. Verdier, V.; Dongo, P.; Boher, B. Assessment of genetic diversity among strains of Xanthomonas campestris pv. manihots. Journal of General Microbiology, Reading, v.139, p.2591-2601, 1993. 